\title{
Synthesis of a New Spirolactone: 7,10-Dimethoxy-1-oxaspiro[4,5]deca-6,9-diene-2,8-dione
}

\author{
Guy L. Plourde (Corresponding author) \\ Department of Chemistry, University of Northern British Columbia \\ 3333 University Way, Prince George, BC V2N 4Z9, Canada \\ Tel: 1-250-960-6694Ｅ-mail: plourde@unbc.ca \\ Mark D. Fairchild \\ Department of Chemistry, University of Northern British Columbia \\ 3333 University Way, Prince George, BC V2N 4Z9, Canada \\ E-mail: markdfairchild@gmail.com \\ Gurkaran S. Sarohia \\ Department of Chemistry, University of Northern British Columbia \\ 3333 University Way, Prince George, BC V2N 4Z9, Canada \\ E-mail: sarohiag@unbc.ca
}

Received: November 21, $2011 \quad$ Accepted: December 9, $2011 \quad$ Published: February 1, 2012

doi:10.5539/ijc.v4n1p2

URL: http://dx.doi.org/10.5539/ijc.v4n1p2

\begin{abstract}
The title compound was synthesized in $36 \%$ yield by oxidative spiroannulation of the corresponding 2,4,5-trisubstituted phenol. Interestingly, this phenol was prepared in $57 \%$ yield from another spirocompound, namely 7-methoxy-1-oxaspiro[4,5]deca-6,9-diene-2,8-dione. We have speculated that the formation of the phenol was due to a series of reactions involving a conjugate addition of methanol to the original spirolactone followed by aromatization and lactone hydrolysis.
\end{abstract}

Keywords: Spironannulation, Aromatization, Phenols, Oxidation, Lead tetraacetate

\section{Introduction}

As part of our continuing efforts towards the synthesis of natural products from simple spirocompounds such as 1 (Figure 1), our focus for the past few years has been towards the asymmetric synthesis of natural products such as the Aranorosins (Mukhopadhyay et al., 1997; Roy et al., 1992; Watanabe et al., 2003), Gymnastatins (Amagata et al., 1998a; Amagata et al., 1998b; Numata et al., 1997; Phoon et al., 2004) and Manumycins (Hu et al., 2001; Sattler et al., 1998). A representative example from each natural product family is shown in Figure 1, Aranorosin 2, Gymnastatin E 3 and Nisamycin 4. As can be seen in Figure 1, all of the natural products have a similar feature, i.e. they all possess at least one epoxide functional group in their structure with a carbon skeleton very similar to that of simple spirocompound such as $\mathbf{1}$. The first step in our study was to demonstrate the feasibility of preparing optically pure spirocompounds for the purpose of synthesizing these natural products in an asymmetric fashion. We have recently reported the asymmetric synthesis of compounds $(+)-5$ and $(+)-6$ shown in Figure 1. The synthesis was accomplished in 4 steps yielding pure (+)-5 and (+)-6 in around $40 \%$ yield, the key step in these reactions being the diastereoselective oxidative spiroannulation of the appropriately substituted phenols (Plourde et al., 2007; Plourde et al., 2008). As a second step towards the synthesis of these natural products, we recently studied the epoxidation reaction of simple spirocompounds in order to produce structures more closely associated with the natural products found in Figure 1. However, instead of using the optically pure lactones (+)-5 and/or (+)-6, we decided to use $\mathbf{1}$ since we believed it to be a good model to optimize the reaction conditions necessary to control the epoxidation. Spirolactone $\mathbf{1}$ [previously synthesized in 
our laboratory] is easily synthesized in high yield and it bears an electron donating group $\left(\mathrm{OCH}_{3}\right)$ at $\mathrm{C}-7$ which would mimic the electronic nature of the amide functional group found at C-7 in either (+)-5 or (+)-6 (Plourde, 1985). However, while studying the epoxidation reaction of $\mathbf{1}$, we obtained unexpected results which we are reporting herein.

\section{Experimental}

\subsection{General}

Melting points were determined on a hot stage instrument and are uncorrected. Infrared spectra were obtained on a Perkin Elmer System 2000 FTIR. ${ }^{1}$ H-NMR spectra were recorded on a Bruker AMX300 spectrometer at 300 $\mathrm{MHz}$ and chemical shifts are expressed in ppm using TMS as internal standard. ${ }^{13} \mathrm{C}$-NMR spectra were recorded on a Bruker AMX300 spectrometer at $75.4 \mathrm{MHz}$ and chemical shifts are expressed in ppm using residual solvent signal as internal standard. Mass spectra (EI) were recorded on a Varian CP-3800 GC system with a Saturn 2200 MS station.

\subsection{Experimental procedures for the synthesis of the title compound}

\subsubsection{3-(4-Hydroxy-2,5-dimethoxyphenyl)propionic acid (10)}

To a solution of spirolactone $1(177 \mathrm{mg}, 0.91 \mathrm{mmol})$ in toluene $(4 \mathrm{~mL})$ was added benzyltrimethylammonium hydroxide ( $40 \%$ in methanol) $(0.8 \mathrm{~mL}, 1.91 \mathrm{mmol}, 2.1$ equiv.). After the appearance of a black precipitate, the mixture was stirred vigorously at room temperature for 1.25 hours. The reaction was quenched by the addition of $10 \%$ aqueous $\mathrm{HCl}(10 \mathrm{~mL})$ and extracted with ethyl acetate $(6 \times 5 \mathrm{~mL})$. The organic fractions were combined, dried $\left(\mathrm{MgSO}_{4}\right)$ and the solvent evaporated in vacuo to afford an orange oil. The crude product was purified by chromatography on silica gel using $25 \%$ hexanes/ethyl acetate as eluent affording a white solid. This product was recrystallized from a $1 / 1$ mixture of ethanol/toluene to afford white flakes $(117 \mathrm{mg}, 57 \%)$. mp: $109-111{ }^{\circ} \mathrm{C}$. IR ( $\mathrm{KBr}) \mathrm{cm}^{-1}: 3479,1715 .{ }^{1} \mathrm{H}-\mathrm{NMR}\left(\mathrm{CDCl}_{3}\right) \delta: 2.63\left(\mathrm{t}, 2 \mathrm{H}, J=7.6 \mathrm{~Hz}, \mathrm{H}_{2}\right), 2.86\left(\mathrm{t}, 2 \mathrm{H}, J=7.6 \mathrm{~Hz}, \mathrm{H}_{3}\right), 3.75(\mathrm{~s}$, $\left.3 \mathrm{H}, \mathrm{OCH}_{3}\right), 3.82\left(\mathrm{~s}, 3 \mathrm{H}, \mathrm{OCH}_{3}\right), 6.54\left(\mathrm{~s}, 1 \mathrm{H}, \mathrm{Ar}-\mathrm{H}_{3}\right), 6.71\left(\mathrm{~s}, 1 \mathrm{H}, \mathrm{Ar}-\mathrm{H}_{6}\right) .{ }^{13} \mathrm{C}-\mathrm{NMR}\left(\mathrm{CDCl}_{3}\right) \delta: 26.0\left(\mathrm{C}_{3}\right), 34.7$ $\left(\mathrm{C}_{2}\right), 56.2\left(\mathrm{OCH}_{3}\right), 57.2\left(\mathrm{OCH}_{3}\right), 99.5\left(\mathrm{Ar}-\mathrm{C}_{3}\right), 113.9\left(\mathrm{Ar}-\mathrm{C}_{6}\right), 119.5\left(\mathrm{Ar}-\mathrm{C}_{1}\right), 140.3\left(\mathrm{Ar}-\mathrm{C}_{4}\right), 145.2\left(\mathrm{Ar}-\mathrm{C}_{5}\right), 152.5$ $\left(\mathrm{Ar}-\mathrm{C}_{2}\right), 179.5(\mathrm{C}=\mathrm{O})$. MS (rel \%) for $\mathrm{C}_{11} \mathrm{H}_{14} \mathrm{O}_{5}: 226$ (100) [M $\left.\mathrm{M}^{+}\right], 224$ (5), 168 (8), 167(32), 165 (4) 164 (2).

\subsubsection{7,10-Dimethoxy-1-oxaspiro[4,5]deca-6,9-diene-2,8-dione (11)}

To a solution of propionic acid $\mathbf{1 0}(92.0 \mathrm{mg}, 0.41 \mathrm{mmol})$ in acetone $(5 \mathrm{~mL})$ was added at room temperature lead tetraacetate (723.0 mg, $1.63 \mathrm{mmol}, 4$ equiv.). The yellow solution was stirred at room temperature for 2 days, filtered through celite $($ and ethylene glycol (5 drops) was added. The solution was stirred at room temperature overnight, filtered through celite $\mathrm{C}$ and evaporated in vacuo to give a yellow solid. The crude product was recrystallized from benzene to afford a yellow solid (33.0 mg, $36 \%)$. mp: 139-142 ${ }^{\circ} \mathrm{C}$. IR $(\mathrm{KBr}) \mathrm{cm}^{-1}: 1728$, 1682. ${ }^{1} \mathrm{H}-\mathrm{NMR}\left(\mathrm{CDCl}_{3}\right) \delta: 2.35\left(\mathrm{~m}, 1 \mathrm{H}, \mathrm{H}_{3 \mathrm{a}}\right), 2.55\left(\mathrm{~m}, 1 \mathrm{H}, \mathrm{H}_{3 \mathrm{~b}}\right), 2.71\left(\mathrm{~m}, 1 \mathrm{H}, \mathrm{H}_{4 \mathrm{a}}\right), 2.74\left(\mathrm{~m}, 1 \mathrm{H}, \mathrm{H}_{4 \mathrm{~b}}\right), 3.73(\mathrm{~s}$, $\left.3 \mathrm{H}, \mathrm{OCH}_{3}\right), 3.81\left(\mathrm{~s}, 3 \mathrm{H}, \mathrm{OCH}_{3}\right), 5.46\left(\mathrm{~s}, 1 \mathrm{H}, \mathrm{H}_{6}\right), 5.55\left(\mathrm{~s}, 1 \mathrm{H}, \mathrm{H}_{9}\right) .{ }^{13} \mathrm{C}-\mathrm{NMR}\left(\mathrm{CDCl}_{3}\right) \delta: 29.2\left(\mathrm{C}_{3}\right), 33.4\left(\mathrm{C}_{4}\right)$, $55.9\left(\mathrm{OCH}_{3}\right), 57.1\left(\mathrm{OCH}_{3}\right), 81.0\left(\mathrm{C}_{5}\right), 101.1\left(\mathrm{C}_{9}\right), 110.1\left(\mathrm{C}_{6}\right), 151.0\left(\mathrm{C}_{7}\right), 172.7\left(\mathrm{C}_{10}\right), 176.6\left(\mathrm{C}_{8}\right), 181.4\left(\mathrm{C}_{2}\right) . \mathrm{MS}$ (rel \%) for $\mathrm{C}_{11} \mathrm{H}_{12} \mathrm{O}_{5}$ : 224(90) $\left[\mathrm{M}^{+}\right], 209(8), 168(10), 167$ (100), 137 (13).

\section{Results and Discussion}

As can be seen in Figure 1, spirocompound 1 possesses two alkene double bonds differing only by the substitution pattern on the vinylic carbons. The first double bond (double bond bearing the $\mathrm{OCH}_{3}$ group) can be considered to be an electron rich double bond (ERDB) due to the presence of the vinylic $\mathrm{OCH}_{3}$ functional group, while the second one (double bond bearing only hydrogen atoms) would be more deficient in electrons and as such considered an electron poor double bond (EPDB) and therefore would be more susceptible to attack by nucleophiles. Hence, by choosing the correct reaction conditions it should be possible to differentiate between these double bonds and carry out the epoxidation reaction only on one of them. Epoxidation involving the use of nucleophilic species would be appropriate to carry out the epoxidation of the disubstituted double bond (EPDB) in 1. Literature precedents suggested that this epoxidation could be done using the hydrogen peroxide anion $\left(\mathrm{HOO}^{-}\right)$in the presence of a phase transfer catalyst as previously described for similar systems (Alcaraz et al., 1998; Enhsen et al., 1990; Moore, 1967; Payne, 1959; Salladie et al., 1987). However, all our attempts to carry out this transformation following this type of procedure failed to give the desired product. Instead, we observed in all cases one major product that we eventually identified as the propionic acid $\mathbf{1 0}$ based on the ${ }^{1} \mathrm{H}$ - and ${ }^{13} \mathrm{C}$-NMR spectral data. ${ }^{13} \mathrm{C}$-NMR data suggested that the new product possessed only one carbonyl group (179.5 ppm) and a second methoxy group could be observed in both the ${ }^{13} \mathrm{C}-\mathrm{NMR}$ (55.9 and $57.1 \mathrm{ppm}$ ) and ${ }^{1} \mathrm{H}-\mathrm{NMR}$ ( 3.75 and $3.82 \mathrm{ppm}$ ). The ${ }^{1} \mathrm{H}-\mathrm{NMR}$ spectrum also showed the presence of only 2 protons in the $6.5-7.0 \mathrm{ppm}$ region suggesting that the 6-membered ring had potentially rearomatized. Furthermore, the fact that only 2 
protons could be found in this region of the spectrum suggested that one of the vinylic proton in $\mathbf{1}$ was substituted during the reaction, most likely by the $\mathrm{OCH}_{3}$ group that we had already identified in the ${ }^{1} \mathrm{H}-\mathrm{NMR}$ spectrum of this product. We speculated that the formation of $\mathbf{1 0}$ probably took place as shown in Figure 2 . This probable mechanism shows that the initial conjugate addition took place with methanol (from the $40 \%$ solution of phase transfer catalyst) instead of the peroxide anion, producing the enolate anion 8. Deprotonation of 8 as shown in Figure 2 would result in the rearomatization of the molecule as well as the lactone ring opening to produce the dianion $\mathbf{9}$. Acidification of $\mathbf{9}$ to produce $\mathbf{1 0}$ was accomplished during the acidic workup. While the lactone ring opening in structure $\mathbf{8}$ is unusual, there is literature precedent suggesting that such ester hydrolysis is possible, yet rare (Barclay et al., 1962). In the case of the transformation suggested in Figure 1 for $\mathbf{8}$ to $\mathbf{9}$, the driving force may simply be the rearomatization of the 6-membered ring which would force the unusual lactone opening to take place. We later found out that the formation of $\mathbf{1 0}$ from $\mathbf{1}$ can be accomplished simply in the presence of the phase transfer catalyst ( $40 \%$ benzyltrimethyl ammonium hydroxide in methanol) and no other reagents are necessary. Hence, we were able to prepare $\mathbf{1 0}$ from $\mathbf{1}$ in $57 \%$ yield using this process as shown in Scheme 1 . We are now attempting to prepare other derivatives by introducing other small alcohols in the reaction mixture and possibly other weak nucleophiles to ascertain the scope of this transformation. We also carried out the spiroannulation reaction of $\mathbf{1 0}$ to produce the new spirolactone $\mathbf{1 1}$ in $36 \%$ yield using a previously reported procedure (Plourde, 2002; Plourde, 2003a-c; Plourde et al., 2005).

\section{Conclusion}

We have successfully prepared a new spirolactone $\mathbf{1 1}$ from phenol $\mathbf{1 0}$ which was produced via the conjugate addition to a simple spirolactone $\mathbf{1}$ followed by rearomatization of the molecule and lactone ring opening. While this reaction is simple in nature, it may provide a new method for the synthesis of other 7,10-disubstituted spirocompounds which are uncommon. We are presently working on the optimization of this process as well as studying this methodology to establish its potential as a general method for forming 7,10-disubstituted spirocompounds.

\section{References}

Alcaraz, L., MacDonald, G., Ragot, J. P., Lewis, N., \& Taylor, R. J. K. (1998). Manumycin A: Synthesis of the (+)-Enantiomer and Revision of the Stereochemical Assignment. J. Org. Chem., 63, 3526-3527. http://dx.doi.org/10.1021/jo980340r

Amagata, T., Doi, M., Ohta, T., Minoura, K., \& Numata, A. (1998a). Absolute stereostructures of novel cytotoxic metabolites, gymnastatin A-E from a Gymnascella species separated from a Halichondria sponge. JCS, Perkin Trans., 1, 3585-3599. http://dx.doi.org/10.1039/A804466J

Amagata, T., Minoura, K., \& Numata, A. (1998b). Gymnasterones, Novel cytotoxic metabolites produced by a fungal strain from a sponge. Tet. Lett., 39, 3773-3774. http://dx.doi.org/10.1016/S0040-4039(98)00613-3

Barclay, L. R. C., Hall, N. D., \& Cooke, G. A. (1962). Mechanism of Alkaline Hydrolysis of Hindered Aromatic Esters, the BAL2 Mechanism. Can J. Chem., 40, 1981-1985. http://dx.doi.org/10.1139N62-304

Enhsen, A., Karabelas, K., Heerding, J. M., \& Moore, H. W. (1990). Synthesis of Hydroxyquinones and Related Compounds. J. Org. Chem., 55, 1177-1185. http://dx.doi.org/10.1021/jo00291a015

Hu, Y., \& Floss, H. G. (2001). New Type II Manumycins produced by Streptomyces nodusus ssp. Asukaensis and their biosynthesis. J. Antibiot., 54, 340-348.

Moore, H. W. (1967). Mono- and Diepoxy-1,4-benzoquinones. J. Org. Chem., 32, 1996-1999.

Mukohopadhyay, T., Bhat, R. G., Roy, R., Yijayakumar, E. K. S., \& Ganguli, B. N. (1997). Aranochlor A and aranochlor B, two new metabolites from Pseudoarachniotus roseus: Production, isolation, structure elucidation and biological properties. J. Antibiot., 51, 439-441.

Numata, A., Amagata, T., Minoura, K., \& Ito, T. (1997). Gymnastatins, Novel cytotoxic metabolites produced by a fungal strain from a sponge. Tet. Lett., 38, 5675-5678. http://dx.doi.org/10.1016/S0040-4039(97)01236-7

Payne, G. B. (1959). Reactions of Hydrogen Peroxide. V. Alkaline Epoxidation of Acrolein and Methacrolein. J. Am. Chem. Soc., 81, 4901-4904.

Phoon, C. W., Somanadhan, B., Heng, S. C. H., Ngo, A., Ng, S. B., Butler, M. S., Buss, A. D., \& Sim, M. M. (2004). Isolation and total synthesis of Gymnastatin N, a POLO-like kinase 1 active constituent from the fungus Arachniotus punctatus. Tetr., 60, 11619-11628. http://dx.doi.org/10.1016/j.tet.2004.09.046

Plourde, G. (1985). Oxidative Spiroannulation of Phenolic Substrates. M.Sc. Thesis, University of Manitoba, 
Winnipeg, Manitoba, Canada.

Plourde, G. L. (2002). Studies towards the diastereoselective spiroannulation of phenolic derivatives. Tet. Lett., 43, 3597-3599. http://dx.doi.org/10.1016/S0040-4039(02)00552-X

Plourde, G. L. (2003a). (+/-)-2-'Butyl-7-methoxy-1-oxaspiro[4,5]deca-6,9-diene-8-one. Molbank, M322.

Plourde, G. L., \& English, N. J. (2005). Diastereoselective Spiroannulation of Phenolic Substrates: Synthesis of (+/-)-2-tert-Butyl-6-methoxy-1-oxaspiro[4.5]deca-6,9-diene-8-one. $\quad$ Molecules, $10, \quad 1335-1339$. http://dx.doi.org/10.3390/10101335

Plourde, G. L., Spaetzel, R. R., Kwasnitza, J. S., \& Scully, T. W. (2007). Diastereoselective Spiroannulation of Phenolic Substrates: Advances Towards the Asymmetric Formation of the Manumycin m- $\mathrm{C}_{7} \mathrm{~N}$ Core Skeleton. Molecules, 12, 2215-2222. http://dx.doi.org/10.3390/12092215

Plourde, G. L., Susag, L. M., \& Dick, D. G. (2008). Determination of the Absolute Configurations of (+)-N-((3S)-3-\{[(4-methylphenyl)sulfonyl]amino\}-1-oxaspiro[4.5]deca-6,9-dien-2,8-dion-7-yl) Acetamide and Benzamide. Molbank, M579.

Plourde, G. L. (2003b). (+/-)-7-Methoxy-2-'propyl-1-oxaspiro[4,5]deca-6,9-diene-8-one Molbank, M319.

Plourde, G. L. (2003c). (+/-)-7-Methoxy-2-methyl-1-oxaspiro[4,5]deca-6,9-diene-8-one Molbank, M316.

Roy, K., Vijayakumar, E. K. S., Mukhopadhyay, T., Chattaerjee, S., Bhat, R. G., Blumbach, J., \& Ganguli, B. N. (1992). Aranorosinol A and aranorosinol B, two mew methobolites from Pseudoarachiniotus roseus: Production, isolation, structure elucidation and biological properties. J. Antibiot., 45, 1592-1598.

Salladie, G., \& Hutt, J. (1987). Total Synthesis of Dihydrovitamin DHV3 and Dihydrotachysterol DHT3, J. Org. Chem., 52, 3560-3566. http://dx.doi.org/10.1021/jo00392a012

Sattler, I., Thiericke, R., \& Zeeck, A. (1998). The Manumycin-group metabolites. Nat. Prod. Rep., 221-240. http://dx.doi.org/10.1039/a815221y

Wanatabe, T., Hashimoto, Y, Yamamoto, K., Hirao, K., Ishihama, A., Hino, M., \& Utsumi, R. (2003). Isolation and characterization of inhibitors of the essential histidine kinase, YycG in Bacillus subtilis and Staphylococcus aureus. J. Antibiot., 56, 1045-1052.

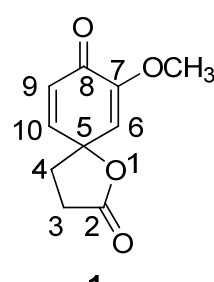

1<smiles>[R]NC1CC23OC2C(=O)OC3O1</smiles>

2 Aranorosin

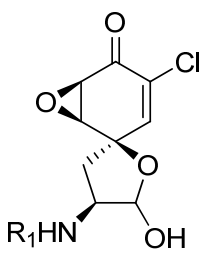

3 Gymnastatin E<smiles>[R]=[V]</smiles><smiles>CCCCCC[C@H](C)/C=C(C)/C=C/C=O</smiles>

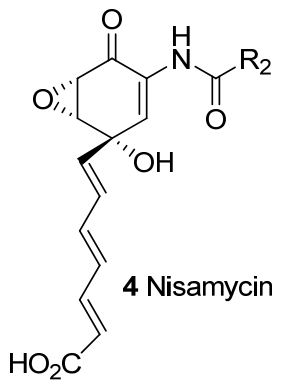<smiles>[R3]C(=O)NC1=CC2(C=CC1=O)C[C@@H](N)C(=O)O2</smiles>

$(+)-5(3 S, 5 R) \mathrm{R}_{3}=\mathrm{CH}_{3}$ $(+)-6(3 S, 5 R) \mathrm{R}_{3}=\mathrm{Ph}$

Figure 1. Structure of Spirolactones and Natural Products<smiles>COCC1=CC(=O)C(OC)=CC12CCC(=O)O2</smiles>

Figure 2. Possible mechanism for the formation of phenol $\mathbf{1 0}$ 


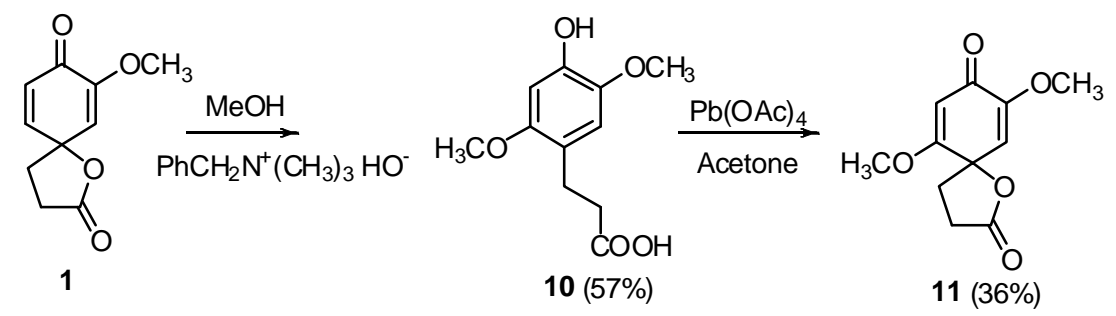

Scheme 1. Synthesis of spirolactone $\mathbf{1 1}$ 